\title{
EVALUATING THE EFFECT OF CROSS SECTIONAL STEEL RATIOS ON CONCRETE DENSITY AND ITS DESIGN IMPLICATION
}

\author{
Safdar Abbas Zaidi*, Muhammad Murtaza Nasir, Muneer Anees and Naveed Jaffer \\ Faculty Department of Civil Engineering, Sir Syed University of Engineering \& Technology, \\ Karachi 75300, Pakistan \\ *Corresponding Author Email: engr.safdarzaidi@gmail.com
}

\begin{abstract}
In this paper, a case study has been taken from construction industry of Pakistan to evaluate the effect of using different percentages of steel rebar's in cross section of structural members. Four different construction sites from Karachi city were surveyed and their heaviest column cross sections were observed for estimating the concrete density. In total sixteen concrete columns are studied in this research and their respective densities calculations were made. Columns are selected in such a way that all have different cross section and different areas of steel in it. From each cross section, the volume of concrete and steel were determined and used to estimate the density of reinforced concrete. The current design density and estimated density is compared and increment in density is calculated. Using the analytical results, a dead load factor for design of structural members is suggested to overcome the effect of increased density of $R C$ members and overall factor of safety were calculated using different ratio of live and dead load at different strength reduction factors.
\end{abstract}

Keywords: Concrete Density, Dead load factor, Factor of safety

Cite this Article: Safdar Abbas Zaidi, Muhammad Murtaza Nasir, Muneer Anees and Naveed Jaffer, Evaluating the Effect of Cross Sectional Steel Ratios on Concrete Density and its Design Implication, International Journal of Civil Engineering and Technology, 11(6), 2020, pp. 72-77.

https://iaeme.com/Home/issue/IJCIET?Volume=11\&Issue=6

\section{INTRODUCTION}

In general, the design unit weight of reinforced concrete has been widely used as 150 pcf. Since concrete is a heterogeneous compound of different materials therefore its density varies with the use of different properties of constituent materials. Especially steel is a major parameter which can bring change in concrete density. According to ACI-318-11, the density of concrete without steel i.e. plain concrete is considered as 144 pcf. Unit weight of concrete, using about $0.7 \%$ to $1.5 \%$ steel may be taken as 150 pcf and for higher steel percentages, the density can be assumed as $155 \mathrm{pcf}$ [1]. Researchers are still studying the effect of constituent materials on the density of concrete and in different countries the standard density varies from 
each other depending on their usual construction practice. In many of the existing or currently being under construction pre-stressed concrete bridge structures in Poland, the designers most often assume the density of concrete as $27 \mathrm{KN} / \mathrm{m} 3$ (crushed stone basalt aggregate concrete) [2]. But now a day's granite or granodiorite crushed aggregates are more common in practice. Such concrete is characterized by a lower density and lower modulus of elasticity then those made using basalt aggregate [3]. As far as plain concrete is concerned it is generally understood that Concretes with specific gravities higher than $2600 \mathrm{~kg} / \mathrm{m} 3$ are called heavy weight concrete [4], but for RCC density may varies with the variation in steel percentage incorporated in cross section.

Addition of high strength steel fibers to concrete [5] results in better ductility and higher load carrying capacity compared to concrete with normal steel fibers, in the absence of main reinforcement bars. Use of optimal steel fiber weight ratio in high strength concrete produces high performance bending elements having elastic-plastic behavior similar to that of normal strength concrete members [6]. The density of reinforced concrete varies with respect to the use of construction purpose as well as design practice in different region. In Pakistan the standard density of RCC structure is considered as 150 pcf neglecting the properties of aggregates and steel ratio in the design industry but it is required to investigate such effect on the construction material i.e. concrete.

\section{METHODOLOGY}

For the sake of investigation 4 random construction sites in Karachi were selected. These sites are named as Royal Park (G+20), Kings Tower $(\mathrm{G}+14)$ and Gold Line Royal Apartments Tower 1 \& $2(\mathrm{G}+13)$. Initially the drawings were collected after a site visit at each construction site and drawings were studied and analyzed with respect to the cross sections and steel ratios employed in it. Since in a frame structure, columns are heavier and thicker than the beams so the focus of this investigation is the column cross section. In order to carry out this research 4 columns from each site were selected depending on the maximum cross section size and maximum steel ratios.

For each column, the calculations for total volume of concrete and steel were estimated as per studied from drawing specifications. For example, the calculations of site Royal Parks has been summarized in Table 1 .

\section{DENSITY CALCULATION}

The density of each selected column is calculated manually in order to compare with the standard concrete density of 150 pcf. The densities of studied columns are also tabulated in table 1. The steps for the calculation of column 1 of Royal Park site are mentioned here,

Note that the hook length, lap length and bent length have been considered in this calculation as per drawing specifications of the given site. Figure 1 shows the detailed description of column 1 for the construction site of Royal Park. It shows the cross section of column at different levels. The calculation for longitudinal steel and shear rings have been done separately and shown in table 2 and 3 respectively. 


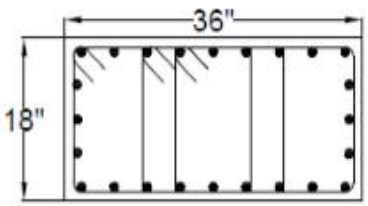

SECTION 9-9

MAIN BARS 24\#

RINGS \#3@6"C/C

Basement \#2 and basement \#1

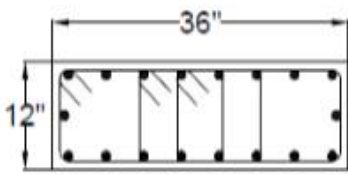

SECTION $11-11$ MAIN BARS $18-\# 8$
RINGS \#3@6"C/C

5th to 8th floor

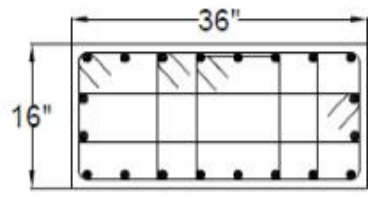

SECTION 2-2 MAIN BARS $20+\#$ RINGS \#3@7 $7^{*} \mathrm{C} / \mathrm{C}$

Ground Floor

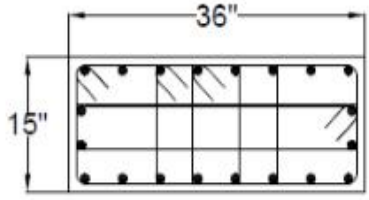

SECTION 3-3

MAIN BARS $20 \# 8$
RINGS \#3@7 $7^{*} \mathrm{CIC}$

First floor and 2nd floor

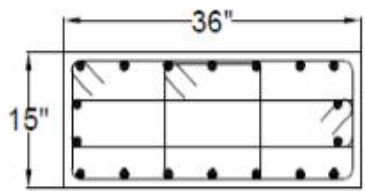

SECTION $10-10$ MAIN BARS 18 \#8

Floor

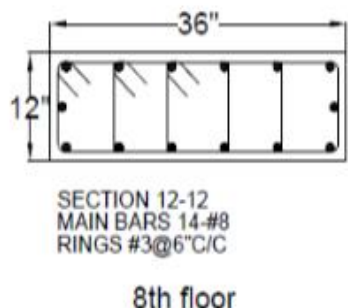

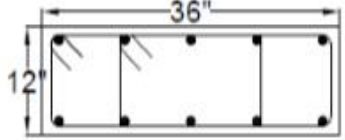

SECTION 6-6 MAIN BARS 10 \#\# RINGS \#3@6"C/C

9th and 10 th floor

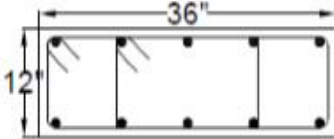

SECTION 7-7

MAIN BARS 10-\#6

RINGS \#3@6"C/C

11 th floor to roof

Figure 1 Detail of cross sections for column 1 at Royal Park site

Table 1 Details of studied columns for each site

\begin{tabular}{|c|c|c|c|}
\hline Column no. & Max. Longitudinal steel at any point (\%) & $\begin{array}{c}\text { Total steel \% } \\
\text { Up to roof }\end{array}$ & $\begin{array}{c}\text { Density } \\
\left(\text { Lb./Ft }^{3}\right)\end{array}$ \\
\hline \multicolumn{4}{|c|}{ Royal Park } \\
\hline Column 1 & 2.182 & 3.198 & 155.066 \\
\hline Column 2 & 2.909 & 3.426 & 155.855 \\
\hline Column 3 & 2.424 & 3.157 & 154.823 \\
\hline Column 4 & 2.424 & 2.816 & 153.8102 \\
\hline \multicolumn{4}{|c|}{ Gold Line Royal Apartment (Tower-1) } \\
\hline Column 1 & 2.864 & 3.239 & 157.14 \\
\hline Column 2 & 1.839 & 2.874 & 154.31 \\
\hline Column 3 & 2.057 & 2.798 & 153.67 \\
\hline Column 4 & 1.023 & 2.619 & 153.06 \\
\hline \multicolumn{4}{|c|}{ Gold Line Royal Apartment (Tower-2) } \\
\hline Column 1 & 2.494 & 4.629 & 157.745 \\
\hline Column 2 & 2.665 & 2.981 & 156.189 \\
\hline Column 3 & 1.317 & 2.837 & 153.817 \\
\hline Column 4 & 1.839 & 3.013 & 153.205 \\
\hline \multicolumn{4}{|c|}{ Kings Tower } \\
\hline Column 1 & 1.621 & 2.428 & 152.39 \\
\hline Column 2 & 1.446 & 2.772 & 153.589 \\
\hline Column 3 & 1.607 & 2.224 & 151.693 \\
\hline Column 4 & 1.227 & 2.175 & 151.5 \\
\hline
\end{tabular}

From these tables the volume of steel can be manipulated by adding the results of table 2 and 3. For concrete volume, figure 1 is sued to calculate the gross cross sectional areas. From the gross area of cross section, the gross volume is estimated and for the net volume of concrete the volume of steel is subtracted from it. For densities estimation the density of plain concrete is assumed for concrete and steel density is considered separately. The summary of calculation for the density of column 1 is shown in table 4. 
Evaluating the Effect of Cross Sectional Steel Ratios on Concrete Density and its Design Implication

Table 2 Calculation of longitudinal steel for column 1 at Royal Park site

\begin{tabular}{|c|c|c|c|c|c|c|}
\hline Column segment & $\begin{array}{c}\text { Ba } \\
\mathbf{r} \\
\text { no. }\end{array}$ & $\begin{array}{c}\text { Area } \\
\text { of bar } \\
\left(\text { in }^{2}\right)\end{array}$ & $\begin{array}{l}\text { Length of } \\
1 \text { bar (in) }\end{array}$ & $\begin{array}{c}\text { No. } \\
\text { of } \\
\text { bars }\end{array}$ & $\begin{array}{l}\text { Volume } \\
\left(\text { in }^{3}\right)\end{array}$ & $\underset{\left(f^{3}\right)}{\text { Volume }}$ \\
\hline $\begin{array}{l}\text { From basement } \# 2 \text { to half of third } \\
\text { floor }\end{array}$ & $\# 8$ & 0.785 & 1207.5 & 18 & $\begin{array}{c}17061.97 \\
5\end{array}$ & 9.874 \\
\hline $\begin{array}{l}\text { From half of third to half of 6th } \\
\text { floor }\end{array}$ & $\# 8$ & 0.785 & 549 & 16 & 6895.44 & 3.990 \\
\hline From half of 6thto half of 8th floor & \#8 & 0.785 & 366 & 14 & 4022.34 & 2.327 \\
\hline From half of $8^{\text {th }}$ to half of 9 th floor & $\# 8$ & 0.785 & 183 & 10 & 1436.55 & 0.83 \\
\hline From half of $9 t$ to half of 19 th floor & \#6 & 0.441 & 1687.5 & 10 & 7441.875 & 4.307 \\
\hline \multirow{2}{*}{$\begin{array}{l}\text { From half } 19^{\text {th }} \text { to roof ( top of 20th } \\
\text { floor ) }\end{array}$} & $\# 8$ & 0.785 & 274.5 & 4 & 861.93 & 0.499 \\
\hline & $\# 6$ & 0.441 & 274.5 & 6 & 726.327 & 0.420 \\
\hline & & \multicolumn{4}{|c|}{ Total longitudinal steel volume } & 22.249 \\
\hline
\end{tabular}

Table 3 Calculation of Shear ring steel for column 1 at Royal Park site

\begin{tabular}{|l|c|c|c|c|c|c|}
\hline \multicolumn{1}{|c|}{ Column segment } & $\begin{array}{c}\text { Bar } \\
\text { no. }\end{array}$ & $\begin{array}{c}\text { Area of bar } \\
\text { (in } \mathbf{2})\end{array}$ & $\begin{array}{c}\text { Length } \\
\text { of 1 bar } \\
\text { (in) }\end{array}$ & $\begin{array}{c}\text { No. of } \\
\text { stirrups }\end{array}$ & $\begin{array}{c}\text { Volume } \\
\text { (in }^{\mathbf{3}} \text { ) }\end{array}$ & $\begin{array}{c}\text { Volume } \\
\text { (ft }^{\mathbf{3}} \text { ) }\end{array}$ \\
\hline $\begin{array}{l}\text { From basement\#2 to 2nd } \\
\text { floor }\end{array}$ & $\# 3$ & 0.11 & 244.668 & 102 & 2745.175 & 1.588 \\
\hline For 2nd floor & $\# 3$ & 0.11 & 230.64 & 26 & 659.630 & 0.382 \\
\hline For 3rd \& 4th floor & $\# 3$ & 0.11 & 292.536 & 36 & 1158.442 & 0.670 \\
\hline For 5th and 6th floor & $\# 3$ & 0.11 & 137.28 & 42 & 634.234 & 0.367 \\
\hline For 7th floor & $\# 3$ & 0.11 & 193.2 & 21 & 446.292 & 0.258 \\
\hline For 8th floor & $\# 3$ & 0.11 & 162.996 & 63 & 1129.562 & 0.654 \\
\hline From 11th to 18th floor & $\# 3$ & 0.11 & 161.49 & 168 & 2984.335 & 1.727 \\
\hline From 19th \& 20th floor & $\# 3$ & 0.11 & 162.252 & 42 & 749.604 & 0.434 \\
\hline
\end{tabular}

\section{DENSITY ANALYSIS RESULTS}

An example of analyzing density using a current design practice is elaborated in Tables 2, 3 and 4. Similarly the density for each selected column is estimated and results are plotted in figure 2. From all the calculations the minimum, average and maximum density of concrete has been calculated and shown in figure 3 .

Table 4 Summary of density calculation for column 1 at Royal Park site

\begin{tabular}{|c|c|c|}
\hline \multicolumn{3}{|c|}{ Density Calculations } \\
\hline Total volume of steel in C\# 26 & 28.329 & $\mathrm{Ft}^{3}$ \\
\hline Gross volume & 886.125 & $\mathrm{Ft}^{3}$ \\
\hline Volume of concrete & 857.795 & $\mathrm{Ft}^{3}$ \\
\hline Mass of concrete $=\rho \mathrm{c} \times \mathrm{Vc}$ & 123522.524 & Lbs. \\
\hline Mass of steel $=\rho s \times V s$ & 13881.550 & Lbs. \\
\hline Total mass $=\mathrm{Mc}+\mathrm{Ms}$ & 137404.074 & Lbs. \\
\hline Density of concrete $=\mathrm{M} / \mathrm{V}$ & 155.062 & $\mathrm{Lb} / \mathrm{Ft} 3$ \\
\hline
\end{tabular}




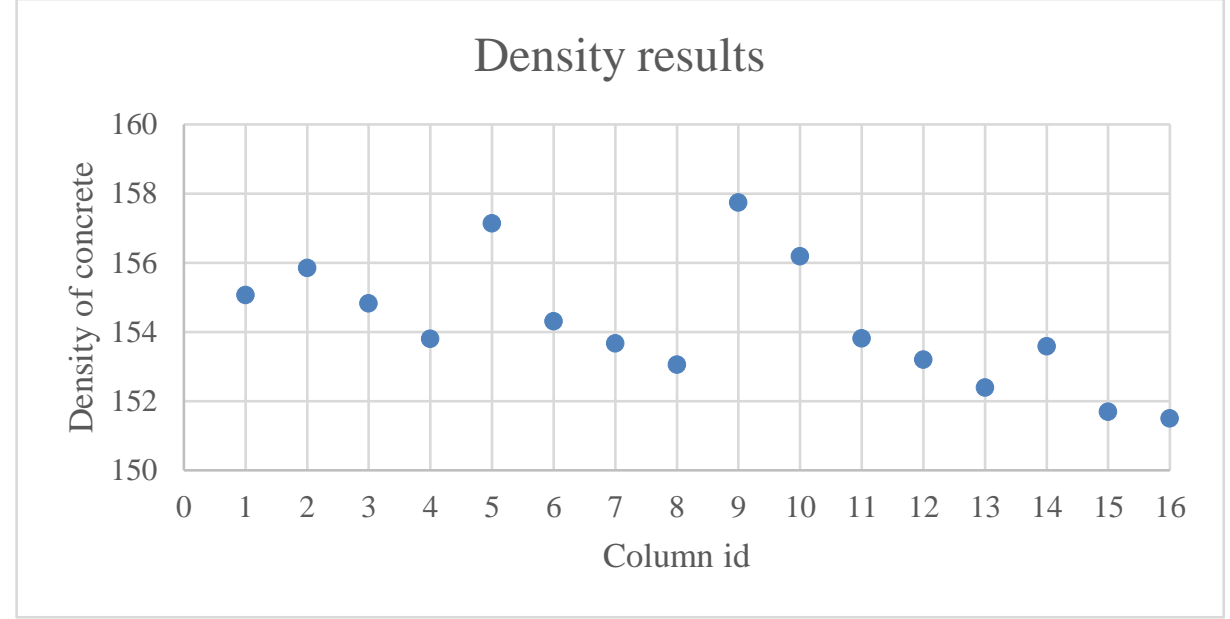

Figure 2 Results of scatter in concrete densities

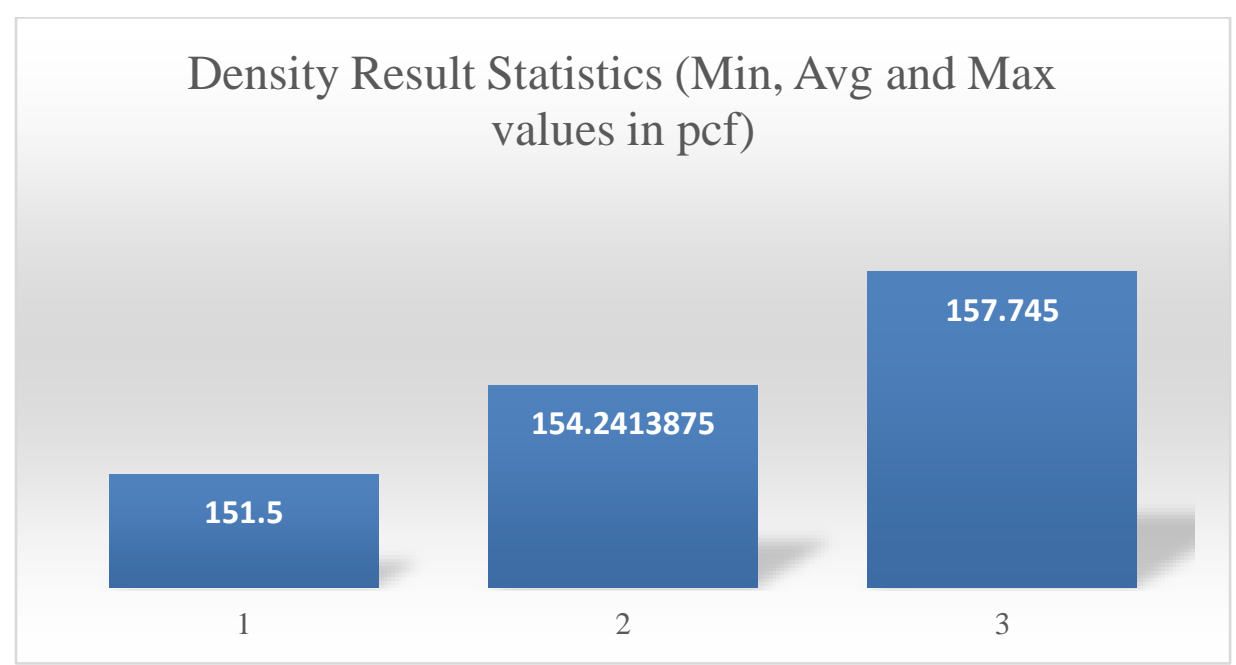

Figure 3 Minimum, Average and Maximum densities

\subsection{Design Implications on Dead Load Factor}

Concrete density and the ratio of live load to dead load are among most critical parameters which describes the variation in load factors of a design code. Figure 3 shows that the minimum density of concrete is even found to be greater than the code value of $150 \mathrm{pcf}$. The maximum increment observed is $8 \mathrm{pcf}$ in addition to the design density of $150 \mathrm{pcf}$. The increment is roughly $5 \%$ in its dead load and to counter the effect of additional weight, dead load factor is modified as below,

Dead load factor $=1.2 \mathrm{D}+5 \% \mathrm{D}$

Dead load factor $=1.25 \mathrm{D}$

Since no data is available for the variation in live load, hence taking same value given by ACI-318-11 and dead load factor of 1.25, overall factor of safety is suggested in table 5.

Table 5 Factor of safety for various values of Phi and L/D

\begin{tabular}{|c|c|c|c|c|c|c|c|c|c|}
\hline Phi & \multicolumn{3}{|c|}{0.9} & \multicolumn{3}{c|}{0.8} & \multicolumn{3}{c|}{0.75} \\
\hline L/D & 1 & 2 & 3 & 1 & 2 & 3 & 1 & 2 & 3 \\
\hline FOS & 1.583 & 1.648 & 1.68 & 1.781 & 1.854 & 1.89 & 1.9 & 1.977 & 2.01 \\
\hline
\end{tabular}


Table 5 shows an overall increased factor of safety relative to ACI suggestions with a little variation. Therefore, it is recommended to use 1.25 as a dead load factor with the modified densities of concrete.

\section{CONCLUSIONS}

- For a normal concrete, a density of $155 \mathrm{pcf}$ is suggested with this research

- For heavy weight concrete the density should be taken as 160 pcf.

- A dead load factor of 1.25 D is recommended for structural design

\section{REFERENCES}

[1] Hassoun, M. N., and Al-Manaseer, A. "Structural Concrete-Theory and Design," John Wiley \&Sons, Inc. USA, (2008)

[2] J. Biliszczuk, "Several remarks on design of prestressed concrete bridges," Conference 'Bridge Durability', DWE, Wrocáaw (2012), pp. 375-384

[3] Przemysław Mossakowski, Wojciech Trochymiak, Wojciech Radomski, "The impact of using concrete of different density on the state of prestressed concrete flyovers over highways," International Conference on Analytical Models and New Concepts in Concrete and Masonry Structures AMCM'2017, Procedia Engineering 193 (2017) pp. 258-265

[4] Salah A. Abu El-Enein, Hamdy A. El-Sayed, Ali H. Ali, Yasser T. Mohammad, Hisham M. Khater, Ahmed S. Ouda., "Physico-Mechanical properties of high performance concrete using different aggregates in presence of silica fume," HBRC Journal. (2014), volume 10, pp: 43-48

[5] K. Holschemacher, T. Müller, H. Kieslich, "Flexural behavior of high-strength concrete with combined steel fiber and bar reinforcement," Proceedings of the International Seminar on "Advanced Concrete Technology and its Applications", (2014), 45-51.

[6] I. Iskhakov, Y. Ribakov, K. Holschemacher, T. Müller, "Experimental investigation of full scale two-layer reinforced concrete beams," Mechanics of Advanced Materials and Structures, (2014), 21, 273-283.

[7] American Concrete Institute Building Design Code, ACI-318-11 